\title{
1 Nitrogen-doped graphene-based materials for advanced oxidation processes
}

2 R.P. Rocha, A.G. Gonçalves, L.M. Pastrana-Martínez, B.C. Bordoni, O.S.G.P. Soares,

3 J.J.M. Órfão, J.L. Faria, J.L. Figueiredo, A.M.T. Silva*, M.F.R. Pereira

4 Laboratory of Catalysis and Materials - Associate Laboratory LSRE/LCM, Faculty of 5 Engineering, University of Porto, Rua Dr. Roberto Frias, 4200-465 Porto, Portugal;

6 *adrian@fe.up.pt

7

\section{Abstract}

9 Nitrogen-doped graphene-based materials were prepared by the modified Hummers

10 method using natural graphite as primary precursor, followed by chemical and thermal

11 reduction processes, and finally ball milled with urea or melamine. The graphene-based

12 materials were characterized at different stages of their synthesis by different techniques

13 (including temperature programmed desorption and X-ray photoelectron spectroscopy)

14 and then tested as metal-free catalysts in the degradation of oxalic acid and phenol by

15 two different oxidation processes: catalytic wet air oxidation (temperature between 413

16 and $433 \mathrm{~K}$, and 7 bar of $\mathrm{O}_{2}$ ) and catalytic ozonation (room temperature and atmospheric

17 pressure). The melamine treated sample was always found to be more active due to the presence of nitrogen groups and adequate surface area available.

Keywords: Metal-free catalysts; graphene-based materials; nitrogen-doping; liquidphase oxidation; water treatment.

\section{Introduction}

24 The abatement of environmental pollution and especially the availability of clean water

25 are among the most significant concerns of society. Advanced oxidation processes 
26 (AOPs), based on the production and use of strongly reactive radicals, can decisively

27 contribute to water purification. In particular, wet air oxidation (WAO) and ozonation

28 are well-established AOPs that have been applied worldwide to treat highly polluted

29 industrial wastewaters and sludge [1-3]. In these processes, oxygen and ozone are

30 respectively used to generate active species capable of oxidizing the organic

31 compounds, preferentially into carbon dioxide and water, or alternatively into easily

32 biodegradable by-products [4].

33 Although metal-based catalysts have been playing a major role to enhance the efficiency

34 of AOPs [5, 6], they often suffer from some disadvantages, such as high cost and 35 detrimental environmental effects due to the catalyst residues. Owing to their 36 environmental compatibility and unique surface properties, carbon nanomaterials have 37 recently demonstrated to be promising metal-free alternatives in catalytic wet air 38 oxidation (CWAO) and catalytic ozonation. In addition, oxygen and nitrogen 39 functionalities can play the role of active sites on carbon materials, the most effective 40 for environmental catalysis being the basic sites [7]. In this sense, different types of 41 carbon materials with nitrogen (including carbon xerogels, carbon nanotubes, and 42 carbon foams and fibres) have been tested in CWAO [4, 8-11] and in ozonation process $43[4,8,12,13]$.

44 Since its isolation and characterization in 2004 [14], graphene and derivatives have 45 emerged as materials of great interest due to their remarkable mechanical, thermal, 46 optical and electrical properties [15, 16]. In particular, graphene oxide (GO) has 47 attracted huge interest as a graphene precursor because oxygen functional groups 48 attached on the GO surface can be partly removed, resulting in the partial restoration of 49 the conjugated structure $[17,18]$. 
50 In the present work, to the best of our knowledge, nitrogen-doped graphene-based

51 materials were tested as metal-free catalysts in AOPs for the first time, namely in

52 CWAO and ozonation. The materials were characterized at different stages of their

53 synthesis by several techniques, including temperature programmed desorption and X-

54 ray photoelectron spectroscopy, and used as catalysts for the mineralization of oxalic

55 acid and phenol in aqueous solutions. Oxalic acid is a refractory short chain carboxylic

56 acid appearing as end-product in other advanced oxidation processes, while phenol is a

57 more complex molecule extensively studied in the literature (usually used as probe

58 species to evaluate the process efficiency) which is also an organic pollutant commonly

59 found in industrial effluents.

60

61 2. Experimental

$62 \quad$ 2.1. Materials

63 2.1.1. Synthesis of graphene oxide

64 GO was synthesized from natural graphite $(20 \mu \mathrm{m}$, Sigma-Aldrich), by a modified 65 Hummers method $[19,20]$. Briefly, $50 \mathrm{~mL}$ of concentrated sulphuric acid was slowly 66 added, under appropriate cooling and stirring conditions, to a flask containing $2 \mathrm{~g}$ of 67 graphite. Then, $6 \mathrm{~g}$ of potassium permanganate were slowly added to the mixture and the suspension kept at $35^{\circ} \mathrm{C}$ for $2 \mathrm{~h}$ under stirring. The solution was diluted in $350 \mathrm{~mL}$

69 of distilled water. Afterwards, $\mathrm{H}_{2} \mathrm{O}_{2}(30 \%$ w/v) was added in order to reduce residual

70 permanganate to soluble manganese ions. The oxidized material was purified with an

71 hydrochloric acid solution (10 wt.\%) and the suspension was then filtered, washed several times with distilled water until the neutrality of the rinsing waters was reached, and dried at $60{ }^{\circ} \mathrm{C}$ for $24 \mathrm{~h}$ to obtain graphite oxide. The resulting material was 
dispersed in a given volume of water and sonicated in an ultrasound bath (ultrasonic processor UP400S, $24 \mathrm{kHz}$ ) for $1 \mathrm{~h}$, GO being obtained in this way

76

\subsubsection{Incorporation of $\mathbf{N}$-functionalities}

The GO material was subjected to mechanical treatments in a ball milling Retsch M200 equipment. The conditions used were selected from a previous work, where the preparation of $\mathrm{N}$-doped carbons by ball milling was proposed and optimized [21]. $0.6 \mathrm{~g}$ of GO was mixed with $0.26 \mathrm{~g}$ of $\mathrm{N}$ using urea or melamine as nitrogen precursor and the mixture was ball-milled during $4 \mathrm{~h}$ at a constant frequency of 15 vibrations/s. Then, the resulting materials were subjected to a thermal treatment under $\mathrm{N}_{2}$ flow $\left(100 \mathrm{~cm}^{3}\right.$ $\min ^{-1}$ ) until $600{ }^{\circ} \mathrm{C}$ (at $2{ }^{\circ} \mathrm{C} \min ^{-1}$ ) and kept at the maximum temperature during $1 \mathrm{~h}$. Partial reduction of GO occurs during the thermal treatment. The reduced GO materials are denoted as $\mathrm{rGO}-\mathrm{U}$ (prepared with urea) or $\mathrm{rGO}-\mathrm{M}$ (prepared with melamine). Reduced GO was also prepared by using the same procedure (mecanichal and thermal treatment), but without addition of a nitrogen source (rGO).

89

\section{$90 \quad$ 2.2. Catalyst characterization}

91 The textural characterization of the materials was based on the $\mathrm{N}_{2}$ adsorption isotherms 92 determined at $-196{ }^{\circ} \mathrm{C}$ with a Quantachrome Nova 4200e apparatus. The nature and 93 amounts of the surface oxygenated groups were determined by temperature 94 programmed desorption (TPD), carried out in an Altamira Instruments AMI-300 apparatus connected to a Dycor Dymaxion Mass Spectrometer. The $\mathrm{pH}$ at the point of zero-charge $\left(\mathrm{pH}_{\mathrm{PZC}}\right)$ was determined by using a drift method described elsewhere [22,

97 23]. Elemental analysis was performed on a Carlo Erba instrument, model EA 1108 and X-ray photoelectron spectroscopy (XPS) performed in a Kratos AXIS Ultra HSA using 

mode (Fixed Analyser Transmission), with a pass energy of $40 \mathrm{eV}$ for regions of interest and $80 \mathrm{eV}$ for survey.

\subsection{Experimental procedure}

104 Catalytic wet air oxidation (CWAO) experiments with phenol and oxalic acid aqueous

105 solutions were performed in a $160 \mathrm{~mL}$ 316-SS high pressure batch reactor housing a 106 glass liner (Parr Instruments, USA Mod. 4564). $100 \mathrm{mg}$ of the catalyst were added to 75

$107 \mathrm{~mL}$ of the organic pollutant solution and placed into the reactor. The reactor was flushed

108 with pure nitrogen until complete removal of oxygen, pressurized with 5 bar of nitrogen

109 and then pre-heated up to the desired temperature under continuous stirring at $500 \mathrm{rpm}$

110 in order to ensure proper mass transfer of oxygen in the liquid phase $[24,25]$. When the

111 desired temperature was reached, pure air was injected to obtain a total pressure of 40

112 bar inside the reactor (corresponding to 7 bar of oxygen partial pressure), this being

113 considered time zero for the reaction. CWAO of oxalic acid was performed at $413 \mathrm{~K}$

114 (1000 $\mathrm{mg} \mathrm{L}^{-1}$ of oxalic acid as starting solution) and phenol experiments at $433 \mathrm{~K}$ (75

$115 \mathrm{mg} \mathrm{L}^{-1}$ of phenol as starting solution) [26]. In addition, non-catalytic wet air oxidation

116 (WAO) runs were carried out with air in the absence of catalyst and adsorption

117 experiments were also performed in the autoclave under similar experimental conditions

118 but replacing air by pure nitrogen (40 bar of total pressure). The carbon materials were

119 recovered at the end of each run for further characterization.

120 Ozonation experiments with the same pollutants (oxalic acid and phenol) were

121 performed at room temperature and pressure in a stirred semi-batch tank reactor. Ozone

122 generated from pure oxygen, using a BMT $802 \mathrm{X}$ ozone generator, was bubbled into the

123 bulk of the solution using a diffusor (total flow rate $=150 \mathrm{~cm}^{3} \mathrm{~min}^{-1}$; ozone 
124 concentration $=50 \mathrm{~g} \mathrm{~m}^{-3}$ ). Ozone in the gas phase was monitored using a BMT 964

125 ozone analyser. In each ozonation experiment the reactor was filled with $700 \mathrm{~mL}$ of a

126 solution containing $90 \mathrm{mg} \mathrm{L}^{-1}$ of oxalic acid or $75 \mathrm{mg} \mathrm{L}^{-1}$ of phenol, at natural $\mathrm{pH} .100$

$127 \mathrm{mg}$ of catalysts were introduced into the reactor before starting gas flow admission and

128 kept in suspension by stirring at $200 \mathrm{rpm}$. Single ozonation experiments (without 129 catalyst) were also performed.

\section{$131 \quad 2.4$ Analytical techniques}

132 Samples periodically withdrawn from the reactors were analysed by high performance

133 liquid chromatography (HPLC) with a Hitachi Elite LaChrom system equipped with a

134 Diode Array Detector (L - 2450). A Bio-Rad Aminex HPX-87H column $(300 \mathrm{~mm} \times 7.8$

$135 \mathrm{~mm}$ ) and $\mathrm{a}_{2} \mathrm{SO}_{4}$ solution $(4 \mathrm{mM})$ at a flow rate of $0.6 \mathrm{~mL} \mathrm{~min}^{-1}$ (as mobile phase)

136 were used for the determination of oxalic acid concentration in the CWAO experiments.

137 The quantification of oxalic acid was performed at $\lambda=210 \mathrm{~nm}$. In the ozonation

138 experiments, the concentration of oxalic acid in solution was determined with an

139 Alltech OA-1000 chromatography column using an isocratic $5 \mathrm{mM} \mathrm{H}_{2} \mathrm{SO}_{4}$ mobile phase

140 at $0.5 \mathrm{~mL} \mathrm{~min}{ }^{-1}$. Quantification of the organic acid was made at $200 \mathrm{~nm}$. In phenol

141 oxidation experiments, the samples were analysed in a Purospher Star RP-18 endcapped

142 column $(250 \mathrm{~mm} \times 4.6 \mathrm{~mm}, 5 \mu \mathrm{m}$ particles $)$ working at room temperature at a fixed

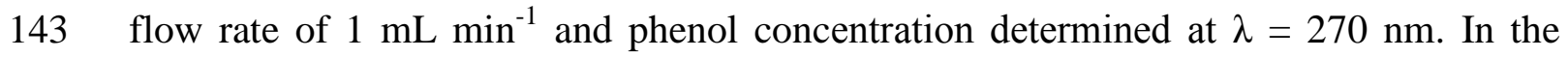

144 CWAO experiments, the mobile phase was a mixture of water and methanol 40/60

145 (v/v). Samples withdrawn from ozonation experiments were analysed using a different

146 method: at first, the column was equilibrated with an A:B (70:30) mixture of ultra-pure

147 water (A) and methanol (B), followed by a linear gradient run to A:B (30:70) in 30 min, 
148 and finally with isocratic elution during $2 \mathrm{~min}$. The total organic carbon (TOC) was also

149 determined using a Shimadzu TOC-5000A analyser.

\section{$151 \quad 3$. Results and discussion}

\section{3.1. Characterization of graphene-based materials}

153 The ball milling and thermal $\left(600^{\circ} \mathrm{C}\right)$ treatments applied to the $\mathrm{GO}$ material promoted

154 several modifications in its textural and chemical properties, as can be seen in Table 1.

155 Regarding the textural properties, the apparent surface area $\left(\mathrm{S}_{\mathrm{BET}}\right)$ increased when GO

156 was subjected to the mecanichal and thermal treatments without addition of a nitrogen

157 source, i.e. from $23 \mathrm{~m}^{2} \mathrm{~g}^{-1}$ (GO) to $263 \mathrm{~m}^{2} \mathrm{~g}^{-1}$ (rGO). This effect could be due to the

158 thermal treatment until $600{ }^{\circ} \mathrm{C}$ since an increase of GO exfoliation with partial reduction

159 to rGO occurs during this step, in addition to the mechanical treatment that can also

160 exfoliate GO and cut the graphene sheets during milling. Nevertheless, this value was

161 significantly lower than the theoretical surface area of $2600 \mathrm{~m}^{2} \mathrm{~g}^{-1}$ for individual

162 isolated graphene sheets [27] mostly due to the partial exfoliation of the graphene

163 sheets, the defective graphene structure formed during the synthesis of GO, and the O-

164 functional groups remaining on rGO.

165 The N-doping of GO using melamine and urea resulted in a decrease of the surface area

166 in comparison with the rGO material $\left(102,47\right.$ and $263 \mathrm{~m}^{2} \mathrm{~g}^{-1}$, for rGO-M, rGO-U and

167 rGO, respectively, Table 1), which suggests that the addition of the N-precursor

168 contributes to a larger aggregation of the graphene sheets, more pronounced when urea

169 is used. Nevertheless, these surface areas are higher than that obtained for the original

170 GO sample $\left(23 \mathrm{~m}^{2} \mathrm{~g}^{-1}\right)$. This effect could be due to the cutting of the graphene sheets

171 that increase the surface area during the ball milling treatment and also due to nitrogen

172 incorporation into the graphene layers. In addition, some agglomeration of the graphene 
173 sheets can occur due to the vibration frequency and duration of the milling used in this

174 work, which are higher than the values normally reported for graphene exfoliation [28].

\section{TABLE 1}

176 The $\mathrm{N}_{2}$ adsorption-desorption isotherms for $\mathrm{rGO}$, rGO-U and rGO-M materials

177 (Figure 1) can be classified as type II, accordingly to IUPAC [29]. In spite of the similar 178 shape of the isotherms, the amounts of $\mathrm{N}_{2}$ adsorbed at the relative pressure $\mathrm{p} / \mathrm{p}_{0}=0.95$

179 are much lower in the case of N-doped samples (rGO-U and rGO-M); these differences 180 may reflect different degrees of agglomeration of the graphene sheets, a result of the 181 different nitrogen precursors used.

\section{FIGURE 1}

183 Figures $2 \mathrm{a}$ and $2 \mathrm{~b}$ represent the TPD profiles corresponding to the groups evolved as

$184 \mathrm{CO}_{2}$ and $\mathrm{CO}$, respectively, from the surface of $\mathrm{GO}, \mathrm{rGO}, \mathrm{rGO}-\mathrm{U}$ and $\mathrm{rGO}-\mathrm{M}$. The total amounts of $\mathrm{CO}_{2}$ and $\mathrm{CO}$ released, the oxygen contents, as well as the $\mathrm{pH}_{\mathrm{PZC}}$ for $\mathrm{GO}$, rGO and N-doped materials are presented in Table 1. The TPD analysis of the graphene-

187 based materials after the thermal treatment reveals a decrease of the oxygen content in 188 the case of rGO (5.6 wt.\%) compared to GO (23.6 wt.\%), which is related to the release 189 of the oxygen-surface groups during the heating until $600{ }^{\circ} \mathrm{C}$, mainly epoxy and 190 hydroxyl groups. After N-doping (both with melamine or urea), a decrease of the 191 oxygen content was also observed, indicating the loss of some oxygenated groups by

192 the incorporation of nitrogen functional groups on the GO material (3.5 and 3.4 wt.\%

193 for rGO-M and rGO-U, respectively).

194 For the rGO and N-doped graphene samples (Figure 2), there is not a different 195 contribution of the type of groups released as $\mathrm{CO}$ and/or $\mathrm{CO}_{2}$ during TPD. In fact most 196 of the surface groups of the samples decomposed as CO (the amount of CO released 197 was always significantly higher than that of $\mathrm{CO}_{2}$, Table 1), namely as phenol and 
198 carbonyl/quinone groups. The presence of these particular groups is linked with the

199 thermal treatment applied; i.e. carbonyl/quinone groups were not removed from the

200 surface since their release occurs at temperatures above $873 \mathrm{~K}$ [30]. On the other hand,

201 the thermal treatments should have removed the most labile oxygen functional groups,

202 namely epoxy and hydroxyl groups located on the basal planes of GO [18], and carboxylic

203 acid and anhydride groups, since they are released at temperatures below $873 \mathrm{~K}$.

204 Phenols and lactones were partially removed since they are decomposed in the range of 205773 to $973 \mathrm{~K}$.

\section{FIGURE 2}

207 The absence (or low content) of acidic surface groups (carboxylic acids, phenol,

208 anhydrides) contributes to the neutral/basic nature of the surface of the graphene-based

209 materials with the samples presenting $\mathrm{pH}_{\mathrm{PZC}}$ values higher than 6 . The incorporation of

210 the surface nitrogen groups (rGO-M and rGO-U samples) contributes with additional

211 electrons, increasing the surface basicity [31] (higher values of $\mathrm{pH}_{\mathrm{pzc}}$ ). Significant

212 amounts of $\mathrm{N}$ (Table 1) were introduced on the surface of the graphene-based materials

213 after the milling treatments (determined by XPS analysis).

214 The sample milled with melamine presents the largest amount of $\mathrm{N}(9.3 \%$ and $7.5 \%$ for

215 rGO-M and rGO-U, respectively). The XPS N1s spectra of the rGO-M and rGO-U

216 samples were decomposed into three peaks (Figures $3 \mathrm{a}$ and $3 \mathrm{~b}$, respectively). The first

217 peak identified at around $398 \mathrm{eV}$, designated as N6, is attributed to pyridinic-N. The

218 second peak, situated ca. $400.0 \mathrm{eV}$, is ascribed to pyrrolic-N, and will be referred as N5.

219 The next peak identified at around $400.9 \mathrm{eV}$ is attributed to quaternary nitrogen (NQ)

$220[32,33]$. However, similar proportions of the different types of nitrogen species were 

with similar proportions, corresponding to $17 \%$ in rGO-M and $25 \%$ in rGO-U.

\section{FIGURE 3}

\subsection{Catalytic tests}

226 The graphene-based materials doped and undoped with nitrogen groups were tested as 227 catalysts in the oxidation of oxalic acid and phenol (used as model pollutants) by

228 CWAO and catalytic ozonation. The catalytic activity of the GO sample was not evaluated in the processes due to its strong acidic character $\left(\mathrm{pH}_{\mathrm{pzc}}<3\right.$, see Table 1$)$, which is well known to have a negative effect on the catalytic performance of carbon materials in the oxidation processes in study $[10,22,26]$.

\subsubsection{Catalytic wet air oxidation}

Figure 4 shows the normalized concentrations of both compounds during the reaction time. Under the operating conditions, both compounds are quite stable and poorly oxidized in the absence of catalysts (WAO curves). However, the conversion of both model pollutants significantly increased by using the graphene-based materials.

\section{FIGURE 4}

239 Figure 4.a shows that total removal of oxalic acid can be achieved in less than 60 min

240 using the graphene-based materials with no by-products being detected by HPLC 241 analysis. Oxalic acid was faster removed from the solution using samples rGO and 242 rGO-M than using the rGO-U sample. However, adsorption contributes to the decay of 243 oxalic acid concentration. Although the adsorption of oxalic acid over the N-doped samples (rGO-M and rGO-U) was lower than $15 \%$ after 60 min, about $30 \%$ of oxalic

245 acid was adsorbed in the case of the rGO sample (reaching about $45 \%$ after $120 \mathrm{~min}$ ).

246 Therefore, the fast removal of the compound under catalytic conditions using the rGO 
247 sample has a significant contribution from adsorption, which cannot be negligible.

248 Besides that, rGO leads to total oxalic acid removal, exhibiting a good catalytic activity

249 for the reaction, probably due to the presence of the $\pi$ electron system of the reduced

250 graphene oxide [17], which contributes to the basicity of the carbon surface [7].

251 Regarding the rGO-M sample, where the adsorption contribution is minor, it seems that

252 the introduction of the nitrogen surface groups leads to an increase of the catalytic

253 performance of the graphene-based material. The worst performance was obtained with

254 the rGO-U sample, more time being required to oxidize oxalic acid completely. This

255 can be due to the lower amount of nitrogen and to the low surface area of the material.

256 In fact, this sample only has $47 \mathrm{~m}^{2} \mathrm{~g}^{-1}$ of specific surface area due to the compaction of

257 the layers during the ball milling treatment with urea, which can decrease the outer

258 surface accessible to oxalic acid. The good catalytic activity of the graphene-based

259 materials for oxalic acid oxidation by $\mathrm{CWAO}$ is related to their surface properties

260 (essentially basic/neutral nature and absence of strong acidic groups), which is in

261 agreement with previous reports using different carbon materials [4, 8, 10, 26, 34, 35].

262 Regarding phenol oxidation experiments (Figure 4.b), once again, the use of the

263 graphene-based materials increases the removal of the pollutant from the solution (that

264 is not converted in the absence of catalyst). In this case, the rGO-M sample clearly

265 exhibits the best catalytic performance (50\% of phenol removal after $120 \mathrm{~min}$ )

266 followed by the rGO and rGO-U samples, with a small contribution of adsorption using

267 samples rGO-M and rGO-U (less than $8 \%$ ). The adsorption experiment using the rGO

268 sample was not performed but it is expected to be higher than this value, as in the oxalic

269 acid case, due to the high surface area of the sample. It is important to note that the

270 CWAO experiments do not lead to total oxidation of phenol; several compounds are

271 involved in the possible reaction pathways of phenol oxidation by CWAO [26, 36], such 
272 as hydroquinone and benzoquinone, which have been identified as the most

273 representative intermediates in the present work. Furthermore, TOC conversions in the 274 oxidation of phenol were low with the rGO-M and rGO-U samples (only 22 and $11 \%$, 275 respectively).

276 The good catalytic performance obtained in the degradation of oxalic acid and phenol 277 by CWAO with the rGO-M sample highlights the positive effect of the nitrogen groups, 278 as already reported in our previous works using different carbon materials (carbon 279 nanotubes [8, 10], carbon xerogels [4] and carbon fibres and foams [9]). In some of the 280 cited works $[4,9]$, linear correlations were found between the model pollutant removal 281 and the amount of $\mathrm{N}$ surface groups.

282 Those dependences may be related with the interaction of oxygen with the carbon 283 surface in the presence of the $\mathrm{N}$ surface groups [37] and the active oxygen species that 284 can be generated [11], which can react with adsorbed organic compounds leading to the 285 oxidation of the organic pollutants. This explanation is also corroborated by some works $286[4,10]$ where it was reported that, in the presence of $\mathrm{N}$ functionalities on the carbon 287 surface, hydroxyl radicals in the liquid phase may not be required, suggesting that the 288 oxidation reaction can occur by an alternative surface reaction mechanism, possibly as 289 described above.

290 An advantage of the use of N-doped carbon materials is the stability of the $\mathrm{N}$ groups. In 291 the oxidation of oxalic acid by CWAO only a slight decrease of the catalytic activity of 292 the materials (carbon nanotubes and carbon xerogels) was observed after the third use $293[4,10]$. Post-reaction analysis of the rGO-M (CWAO) and rGO-U (CWAO) samples by 294 XPS (Figures 3.c and 3.d, respectively) showed that nitrogen functionalities were stable 295 and there are not significant changes of the $\mathrm{N}$ groups after oxalic acid oxidation by 296 CWAO, as also observed with carbon xerogels [4]. 


\subsubsection{Catalytic ozonation}

299 In the present study, the ozonation of oxalic acid at the natural $\mathrm{pH}$ (approximately 3 ) in

300 the presence of the prepared graphene-based materials was investigated. The results are

301 depicted in Figure 5.

\section{FIGURE 5}

303 It was observed that single ozonation only removes about $32 \%$ of the oxalic acid in 304 solution after $2 \mathrm{~h}$, while the addition of the prepared graphene samples significantly 305 enhanced its mineralization. Almost complete degradation of oxalic acid can be 306 achieved in $2 \mathrm{~h}$ using rGO-M, while oxalic acid conversions of $83 \%$ and $75 \%$ were 307 obtained using the rGO and rGO-U samples, respectively.

308 The two different precursors (melamine or urea) used during the preparation of N-doped 309 samples originated two materials with different textural properties and surface

310 chemistry, which led to the different performances when used as ozonation catalysts.

311 Concerning the rGO-M sample, although it presents lower specific surface area than

312 rGO (where oxalic acid and molecular ozone can adsorb and react), this catalyst 313 presents a better performance in the oxalic acid degradation, which may be related to 314 the introduction of the $\mathrm{N}$-surface groups. On the other hand, the worse performance of 315 rGO-U can be due to the very low specific surface area (only $47 \mathrm{~m}^{2} \mathrm{~g}^{-1}$ ) compared to the 316 rGO and rGO-U samples (263 and $102 \mathrm{~m}^{2} \mathrm{~g}^{-1}$, respectively), and the lower amount of

317 nitrogen on the surface when compared to the rGO-M sample.

318 The ozonation of phenol was carried out at the natural solution $\mathrm{pH}$ (approximately 6).

319 Both phenol and TOC decay were followed during $300 \mathrm{~min}$, and the corresponding 320 experimental data are depicted in Figure 6. 
322 It can be observed that ozonation by itself enables a fast decay of the phenol

323 concentration and, under the selected experimental conditions, total conversion of this

324 compound from aqueous solution is achieved in about $60 \mathrm{~min}$. This is because ozone

325 preferentially attacks activated aromatic rings present in compounds, which is the case

326 of phenol. In fact, the $-\mathrm{OH}$ group present in the phenol molecule is electron donating,

327 activating the aromatic ring by increasing its electron density. Furthermore, aromatic

328 compounds such as phenol have a high delocalization of electrons and exhibit improved

329 reactivity towards ozone. There are no significant differences between single ozonation

330 and catalytic ozonation. However, when TOC results are compared (see Figure 6b), the

331 presence of graphene-based materials leads to higher mineralization degrees than single

332 ozonation. Their catalytic performance in ozonation of phenol is similar to those

333 obtained with oxalic acid. Thus, with the simultaneous use of ozone and the rGO-M

334 sample, a mineralization degree of $85 \%$ was achieved after $180 \mathrm{~min}$, whereas a worse

335 mineralization degree was obtained using the rGO-U sample (65\% after $180 \mathrm{~min})$.

336 The oxidation of phenol originated several intermediates and by-products [38].

337 Hydroquinone and p-benzoquinone were identified, representing the main intermediates

338 produced during single and catalytic ozonation of phenol. They are produced in higher

339 amount at the beginning of the reaction (between 15-20 min). Besides these compounds,

340 some other organic compounds, such as, oxalic, maleic and pyruvic acids were found as

341 oxidation by-products of phenol, which are resultant not only from phenol degradation

342 but also from their intermediates. These acids are accumulated in solution, their

343 degradation starting later. After 180 min of ozonation catalysed by rGO-M, oxalic acid

344 is the only acid present in solution. However, in the case of rGO-U and rGO, traces of

345 other non-identified acids persist in solution at the end of the reaction period. 
346 The performance of the graphene-based materials in catalytic ozonation is influenced by

347 their surface chemical properties, similarly to what occurs with activated carbon [35]

348 and carbon nanotubes [22]: in general, this process is favoured by carbon materials with

349 basic/ neutral character $[22,35]$. However, the $\mathrm{pH}$ of the medium plays an important

350 role on the reaction mechanism. In fact, the decomposition of ozone catalysed by

351 graphene-based materials will depend on the solution $\mathrm{pH}$, because of their amphoteric

352 nature, the surface being positively or negatively charged, according to what occurs

353 with other carbon materials $[34,39]$. In case of the oxalic acid solution, the $\mathrm{pH}$ is about

3543 , between the $\mathrm{pKa}_{1}$ (1.23) and $\mathrm{pKa}_{2}$ (4.19) values and, consequently, a fraction of the

355 acid is deprotonated. Therefore, the surfaces of the materials investigated in this work

356 (rGO, rGO-U and r-GO-M), which have a $\mathrm{pH}_{\mathrm{PZC}}$ higher than the $\mathrm{pH}$ of the solution,

357 become positively charged, enhancing the attraction of hydroxide ions and thus, the

358 degradation of oxalic acid. On the other hand, in the case of phenol, the solution $\mathrm{pH}$

359 (approximately 6) is lower than the pKa (9.89), the protonated form being the

360 predominant species. Since the surfaces of the graphene-based materials are positively

361 charged at this $\mathrm{pH}$, there are repulsive electrostatic interactions between the carbon

362 surface and phenol species, disfavouring the mineralization.

363 For the degradation of oxalic acid and phenol, the rGO-M sample led to the best

364 catalytic performance, which evidences a positive effect of the nitrogen groups on the

365 surface of graphene-based materials in the ozonation process. After a first run, the

366 surface of the graphene-based material may present acidic oxygenated groups due to the

367 interaction with ozone, which impairs the catalytic performance; however, no major

368 changes are expected after a second utilization, similarly to what was observed with

369 other carbon materials, such as carbon nanotubes [8], xerogels [4] and activated carbon

$370 \quad[12,13]$. 


\section{Conclusions}

373 The addition of $\mathrm{N}$-groups to the graphene structure markedly affected the catalytic

374 performance of the synthesized materials in the degradation of oxalic acid and phenol,

375 either by CWAO or by catalytic ozonation. Oxalic acid remains refractory to oxidation

376 in the absence of a catalyst, under wet air oxidation conditions, but is efficiently

377 oxidized by CWAO using the N-modified graphene-based materials. Phenol can be

378 converted by single ozonation, but the $\mathrm{N}$-modified graphene-based materials

379 significantly improve its mineralization. For the ozonation process, both oxalic acid and

380 phenol are not completely mineralized without the introduction of graphene-based

381 materials.

382

383 Acknowledgments

384 This work was supported by projects: FREECATS, financed by the European Union 7th 385 FP (2007-2013) grant $n^{\circ}$. 280658; PEst-C/EQB/LA0020/2013, financed by FEDER 386 through COMPETE - Programa Operacional Factores de Competitividade, and by FCT

387 - Fundação para a Ciência e a Tecnologia; NORTE-07-0162-FEDER-000050, NORTE388 07-0202-FEDER-038900 and NORTE-07-0124-FEDER-000015 financed by QREN, 389 ON2 and FEDER. AMTS acknowledges the FCT Investigator 2013 Programme 390 (IF/01501/2013) financed by European Social Fund and the Human Potential 391 Operational Programme. RPR, LMPM, OSGPS, and AGG acknowledge the FCT grants

392 SFRH/BD/95411/2013, SFRH/BPD/88964/2012, SFRH/BPD/80435/2011 and 393 SFRH/BPD/95538/2013, respectively. The authors thank Dr. Carlos Sá at CEMUP for 394 assistance with XPS analyses. 
397 [1] J. Levec, A. Pintar, Catalysis Today, 124 (2007) 172-184.

398 [2] K. Ikehata, M.G. El-Din, Ozone: Science and Engineering, 27 (2005) 173-202.

399 [3] K. Ikehata, M.G. El-Din, Ozone: Science and Engineering, 27 (2005) 83-114.

400 [4] R.P. Rocha, J. Restivo, J.P.S. Sousa, J.J.M. Órfão, M.F.R. Pereira, J.L. Figueiredo, 401 Catalysis Today.

402 [5] K.-H. Kim, S.-K. Ihm, Journal of Hazardous Materials, 186 (2011) 16-34.

403 [6] P.C.C. Faria, D.C.M. Monteiro, J.J.M. Órfão, M.F.R. Pereira, Chemosphere, 74 404 (2009) 818-824.

405 [7] J.L. Figueiredo, M.F.R. Pereira, Catalysis Today, 150 (2010) 2-7.

406 [8] J. Restivo, R.P. Rocha, A.M.T. Silva, J.J.M. Órfão, M.F.R. Pereira, J.L. Figueiredo, 407 Chinese Journal of Catalysis, 35 (2014) 896-905.

408 [9] J.P.S. Sousa, A.M.T. Silva, M.F.R. Pereira, J.L. Figueiredo, Separation Science and 409 Technology, 45 (2010) 1546 - 1554.

410 [10] R.P. Rocha, J.P.S. Sousa, A.M.T. Silva, M.F.R. Pereira, J.L. Figueiredo, Applied 411 Catalysis B: Environmental, 104 (2011) 330-336.

412 [11] H. Chen, G. Yang, Y. Feng, C. Shi, S. Xu, W. Cao, X. Zhang, Chemical 413 Engineering Journal, 198-199 (2012) 45-51.

414 [12] L. Xing, Y. Xie, H. Cao, D. Minakata, Y. Zhang, J.C. Crittenden, Chemical 415 Engineering Journal, 245 (2014) 71-79.

416 [13] H. Cao, L. Xing, G. Wu, Y. Xie, S. Shi, Y. Zhang, D. Minakata, J.C. Crittenden, 417 Applied Catalysis B: Environmental, 146 (2014) 169-176.

418 [14] K.S. Novoselov, A.K. Geim, S.V. Morozov, D. Jiang, Y. Zhang, S.V. Dubonos,

419 I.V. Grigorieva, A.A. Firsov, Science, 306 (2004) 666-669.

420 [15] A.K. Geim, K.S. Novoselov, Nat Mater, 6 (2007) 183-191.

421 [16] A.K. Geim, Science, 324 (2009) 1530-1534.

422 [17] S. Pei, H.-M. Cheng, Carbon, 50 (2012) 3210-3228.

423 [18] L.M. Pastrana-Martínez, S. Morales-Torres, V. Likodimos, P. Falaras, J.L. 424 Figueiredo, J.L. Faria, A.M.T. Silva, Applied Catalysis B: Environmental, 158-159 425 (2014) 329-340.

426 [19] L.M. Pastrana-Martínez, S. Morales-Torres, V. Likodimos, J.L. Figueiredo, J.L. 427 Faria, P. Falaras, A.M.T. Silva, Applied Catalysis B: Environmental, 123-124 (2012) 428 241-256.

429 [20] W.S. Hummers, R.E. Offeman, Journal of the American Chemical Society, 80 430 (1958) 1339-1339.

431 [21] O.S.G.P. Soares, R.P. Rocha, A.G. Gonçalves, J.J.M. Órfão, J.L. Figueiredo, 432 M.F.R. Pereira.

433 [22] A.G. Gonçalves, J.L. Figueiredo, J.J.M. Órfão, M.F.R. Pereira, Carbon, 48 (2010) 434 4369-4381.

435 [23] J. Rivera-Utrilla, I. Bautista-Toledo, M.A. Ferro-García, C. Moreno-Castilla, 436 Journal of Chemical Technology \& Biotechnology, 76 (2001) 1209-1215.

437 [24] H.T. Gomes, B.F. Machado, A. Ribeiro, I. Moreira, M. Rosário, A.M.T. Silva, J.L. 438 Figueiredo, J.L. Faria, Journal of Hazardous Materials, 159 (2008) 420-426.

439 [25] Â.C. Apolinário, A.M.T. Silva, B.F. Machado, H.T. Gomes, P.P. Araújo, J.L. 440 Figueiredo, J.L. Faria, Applied Catalysis B: Environmental, 84 (2008) 75-86.

441 [26] R.P. Rocha, A.M.T. Silva, S.M.M. Romero, M.F.R. Pereira, J.L. Figueiredo, 442 Applied Catalysis B: Environmental, 147 (2014) 314-321.

443 [27] M.D. Stoller, S. Park, Y. Zhu, J. An, R.S. Ruoff, Nano Letters, 8 (2008) 34984443502. 
445 [28] V. Leon, M. Quintana, M.A. Herrero, J.L.G. Fierro, A.d.l. Hoz, M. Prato, E. 446 Vazquez, Chemical Communications, 47 (2011) 10936-10938.

447 [29] K.S.W. Sing, D. H. Everett, R. A. W. Haul, L. Moscou, R. A. Pierotti, J. 448 Rouquerol, T. Siemieniewska Pure and Applied Chemistry, 57 (1985) 603-619.

449 [30] J.L. Figueiredo, M.F.R. Pereira, M.M.A. Freitas, J.J.M. Órfão, Carbon, 37 (1999) $450 \quad 1379-1389$.

451 [31] H.-P. Boehm, Catalytic Properties of Nitrogen-Containing Carbons, Carbon 452 Materials for Catalysis, John Wiley \& Sons, Inc.2008, pp. 219-265.

453 [32] R.J.J. Jansen, H. van Bekkum, Carbon, 33 (1995) 1021-1027.

454 [33] J.P.S. Sousa, M.F.R. Pereira, J.L. Figueiredo, Catalysis Today, 176 (2011) 383455387.

456 [34] P.C.C. Faria, J.J.M. Órfão, M.F.R. Pereira, Industrial \& Engineering Chemistry 457 Research, 45 (2006) 2715-2721.

458 [35] P.C.C. Faria, J.J.M. Órfão, M.F.R. Pereira, Applied Catalysis B: Environmental, 79 459 (2008) 237-243.

460 [36] E.M. Sulman, V.G. Matveeva, V.Y. Doluda, A.I. Sidorov, N.V. Lakina, A.V. 461 Bykov, M.G. Sulman, P.M. Valetsky, L.M. Kustov, O.P. Tkachenko, B.D. Stein, L.M. 462 Bronstein, Applied Catalysis B: Environmental, 94 (2010) 200-210.

463 [37] E. Pollak, G. Salitra, A. Soffer, D. Aurbach, Carbon, 44 (2006) 3302-3307.

464 [38] K. Turhan, S. Uzman, Desalination, 229 (2008) 257-263.

465 [39] A.G. Gonçalves, J.J.M. Órfão, M.F.R. Pereira, Catalysis Communications, 35 466 (2013) 82-87.

467

468 
472 Table 1. Chemical and textural characterization of the graphene-based materials.

\begin{tabular}{|c|c|c|c|c|c|c|c|c|}
\hline \multirow{2}{*}{ Sample } & \multirow{2}{*}{$\begin{array}{c}\mathrm{S}_{\mathrm{BET}} \\
\left(\mathrm{m}^{2} \mathrm{~g}^{-1}\right)\end{array}$} & \multirow{2}{*}{$\begin{array}{c}\mathrm{CO}_{2} \\
\left(\mu \mathrm{mol} \mathrm{g}{ }^{-1}\right)\end{array}$} & \multirow{2}{*}{$\begin{array}{c}\mathrm{CO} \\
\left(\mu \mathrm{mol} \mathrm{g}{ }^{-1}\right)\end{array}$} & \multirow{2}{*}{$\begin{array}{l}\mathrm{O}^{(\mathrm{a})} \\
(\%)\end{array}$} & \multirow{2}{*}{$\mathrm{CO} / \mathrm{CO}_{2}$} & \multicolumn{2}{|c|}{$\mathrm{N}_{\mathrm{XPS}}{ }^{(\mathrm{b})}$} & \multirow{2}{*}{$\mathrm{pH}_{\mathrm{PZC}}$} \\
\hline & & & & & & $(\%)$ & $\mathrm{N} 5 / \mathrm{N} 6$ & \\
\hline GO & 23 & 5305 & 4156 & 23.6 & 0.8 & n.a. & n.a. & 2.8 \\
\hline rGO & 263 & 494 & 2481 & 5.6 & 5.0 & n.a. & n.a. & 6.2 \\
\hline rGO-M & 102 & 405 & 1378 & 3.5 & 3.4 & 9.3 & 0.6 & 7.3 \\
\hline rGO-U & 47 & 262 & 1626 & 3.4 & 6.2 & 7.5 & 0.5 & 8.1 \\
\hline
\end{tabular}

473 (a) determined from the amount of $\mathrm{CO}$ and $\mathrm{CO}_{2}$ released by TPD

474 (b) Nitrogen content obtained from XPS analysis

$475 \quad \mathrm{~N} 5$ - pyrrolic N groups; N6 - Pyridinic N groups

476 n.a. - not applicable

477 


\section{FIGURE CAPTIONS}

479

480 Figure 1. $\mathrm{N}_{2}$ adsorption-desorption isotherms at $77 \mathrm{~K}$ for graphene-based materials.

481

482 Figure 2. $\mathrm{CO}_{2}$ (a) and $\mathrm{CO}$ (b) evolutions in TPD profiles of graphene oxide (GO) and 483 thermally treated graphene-based samples (rGO, rGO-M and rGO-U).

484

485 Figure 3. N1s XPS spectra for the fresh rGO-M (a) and rGO-U (b) samples and after 486 being used in CWAO of oxalic acid (c and d).

487

488 Figure 4. Evolution of the normalized oxalic acid (a) and phenol (b) concentrations 489 under non-catalytic conditions (WAO), adsorption experiments (Ads) and using 490 graphene-based materials as catalysts in CWAO.

491

492 Figure 5. Evolution of normalized concentration of oxalic acid at natural $\mathrm{pH}$ during 493 single and catalytic ozonation $\left(\mathrm{C}_{0 \text {,oxalic acid }}=90 \mathrm{mg} \mathrm{L}{ }^{-1}\right.$, catalysts $=0.14 \mathrm{~g} \mathrm{~L}^{-1}$, $\mathrm{Q}_{\mathrm{gas}}=$ $494150 \mathrm{~cm}^{3} \mathrm{~min}^{-1}, \mathrm{C}_{\mathrm{O} 3 \text {, feeding }}=50 \mathrm{~g} \mathrm{~m}^{-3}$ ).

495

496 Figure 6. Evolution of normalized phenol (a) and TOC (b) concentrations at natural pH 497 during single and catalytic ozonation $\left(\mathrm{C}_{0 \text {,phenol }}=75 \mathrm{mg} \mathrm{L}{ }^{-1}\right.$, catalysts $=0.14 \mathrm{~g} \mathrm{~L}^{-1}$, $\mathrm{Q}_{\text {gas }}=$ $498150 \mathrm{~cm}^{3} \mathrm{~min}^{-1}, \mathrm{C}_{\mathrm{O} 3, \text { feeding }}=50 \mathrm{~g} \mathrm{~m}^{-3}$ ).

499 
500 FIGURE 1

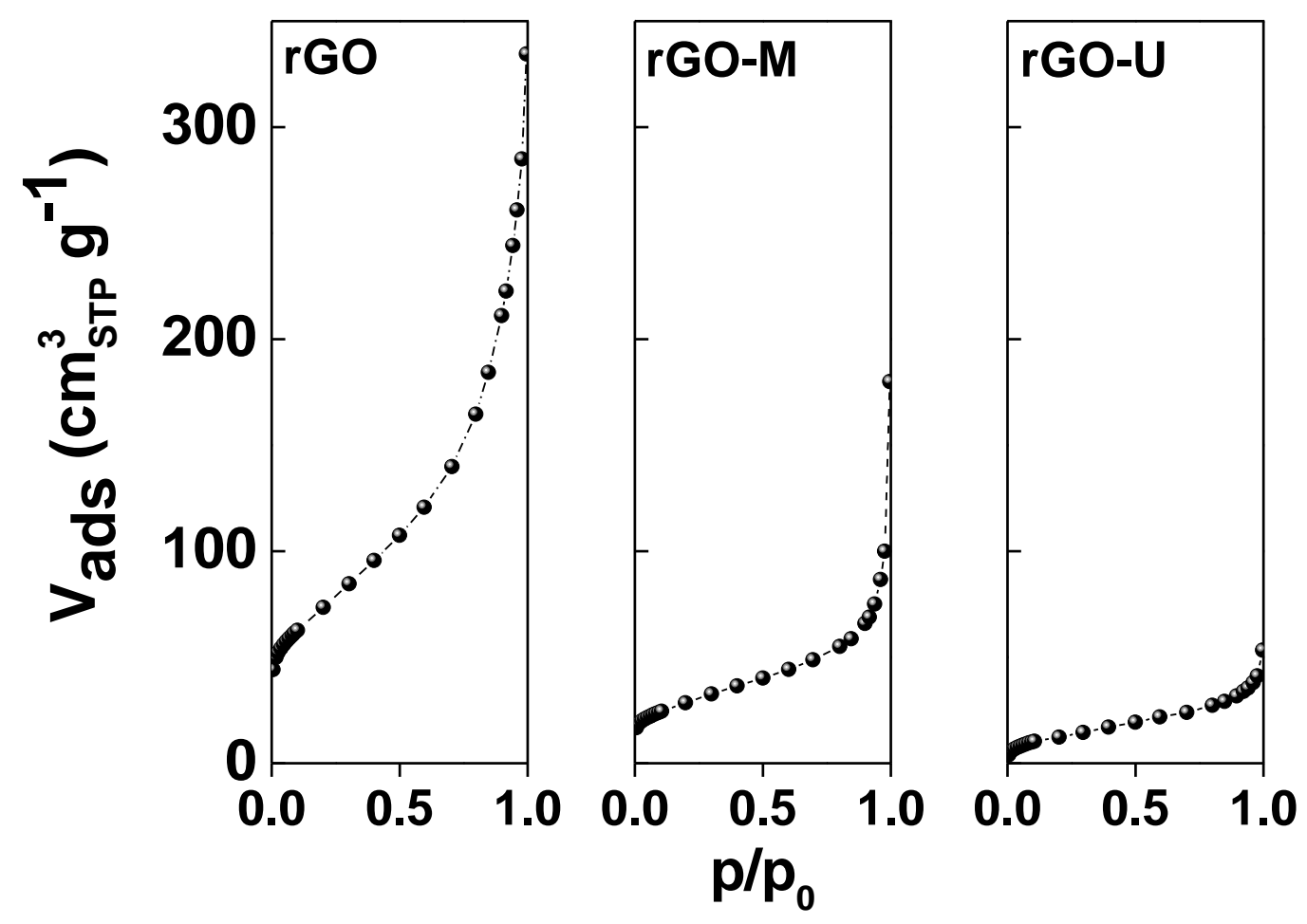

501 
503

a.

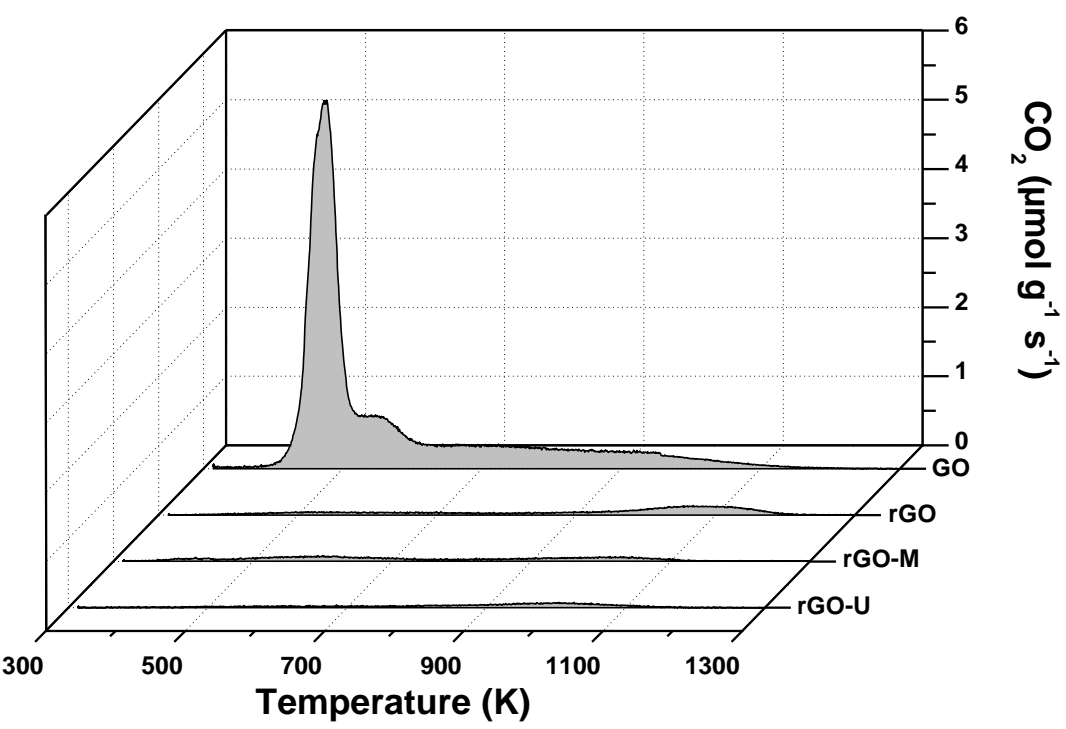

504

b.

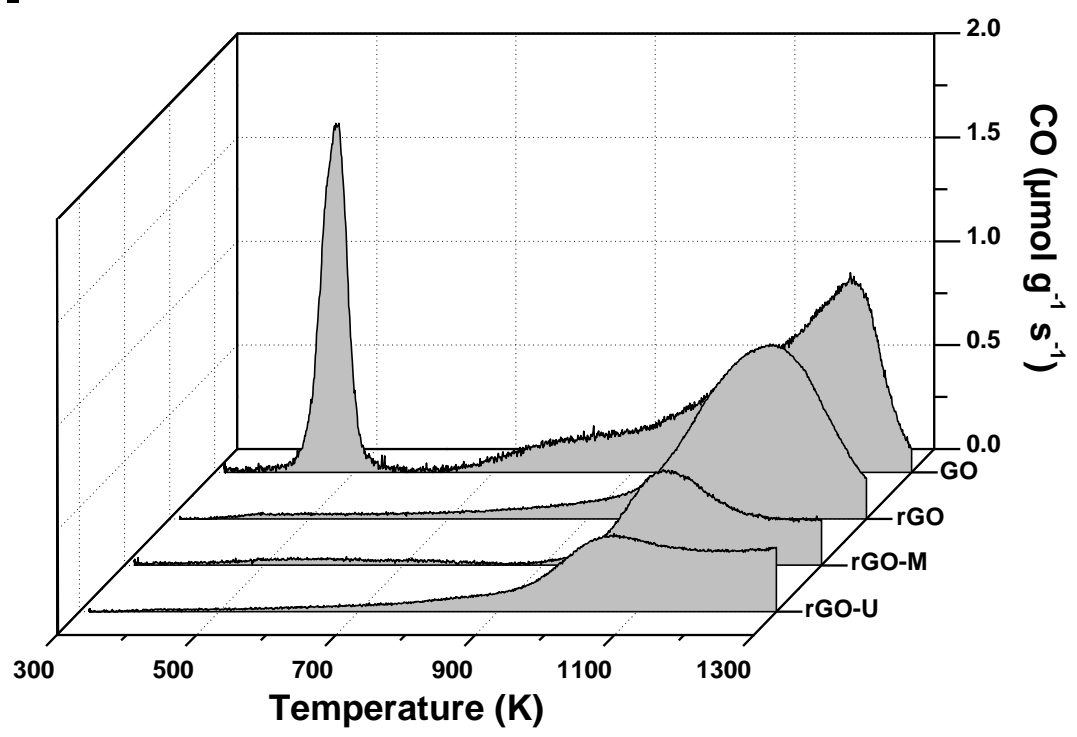

506

507

508

509 
FIGURE 3

a.

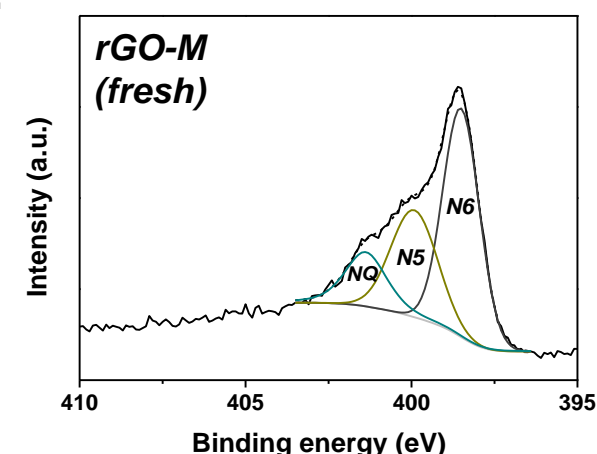

511

c.

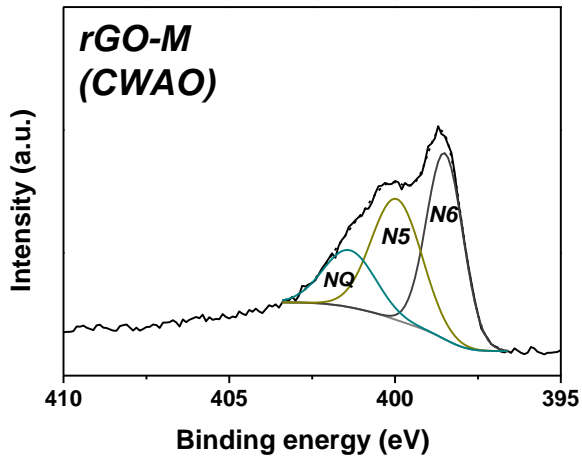

b.

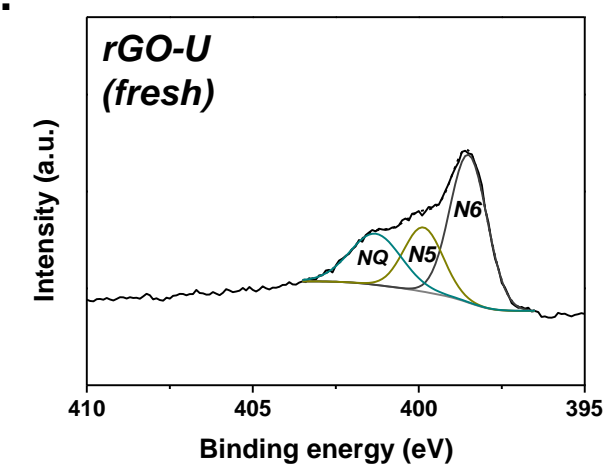

d.

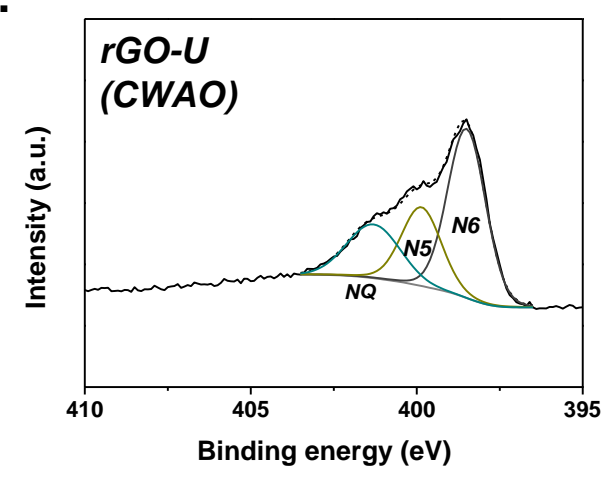


514 FIGURE 4
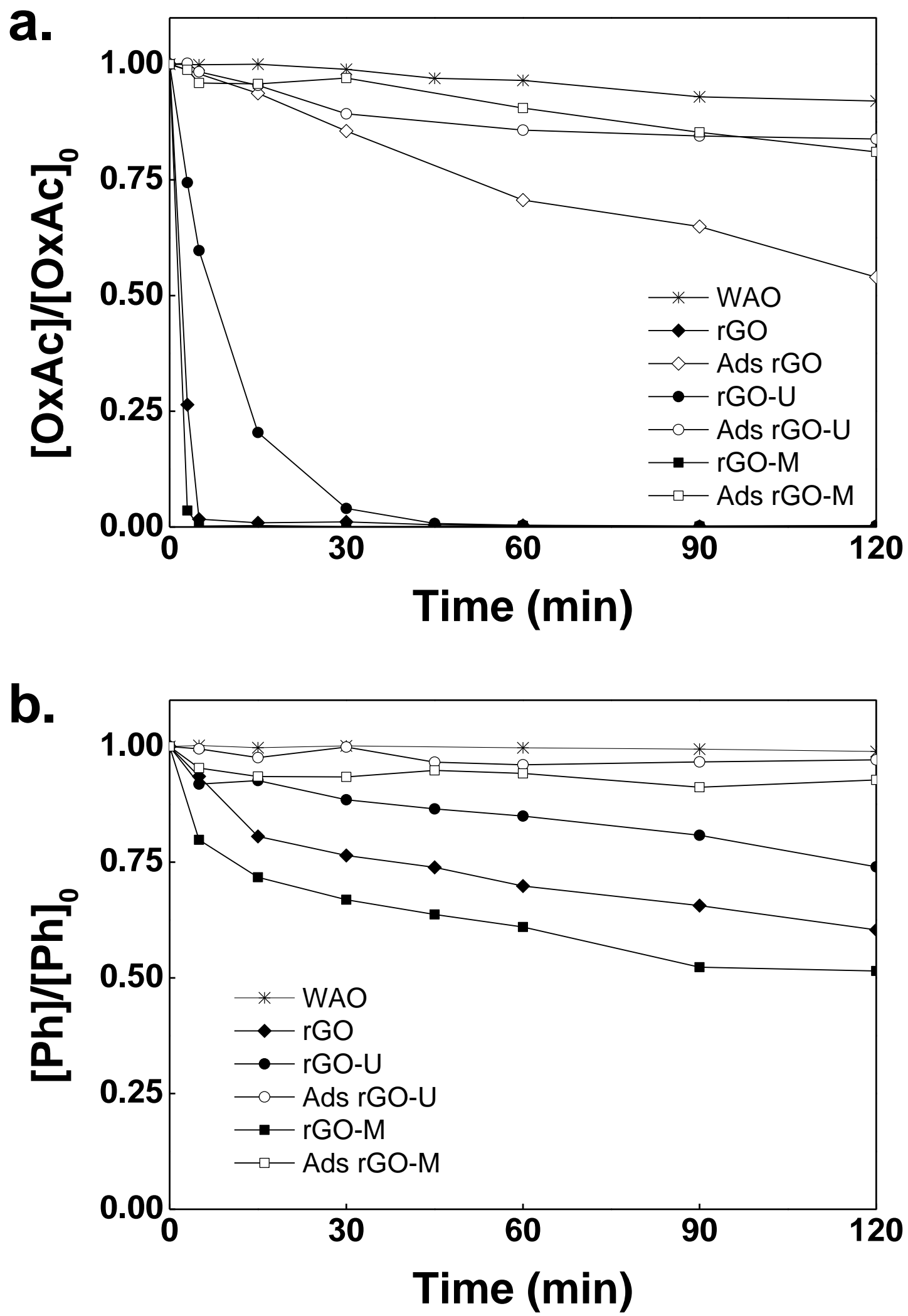
518 FIGURE 5

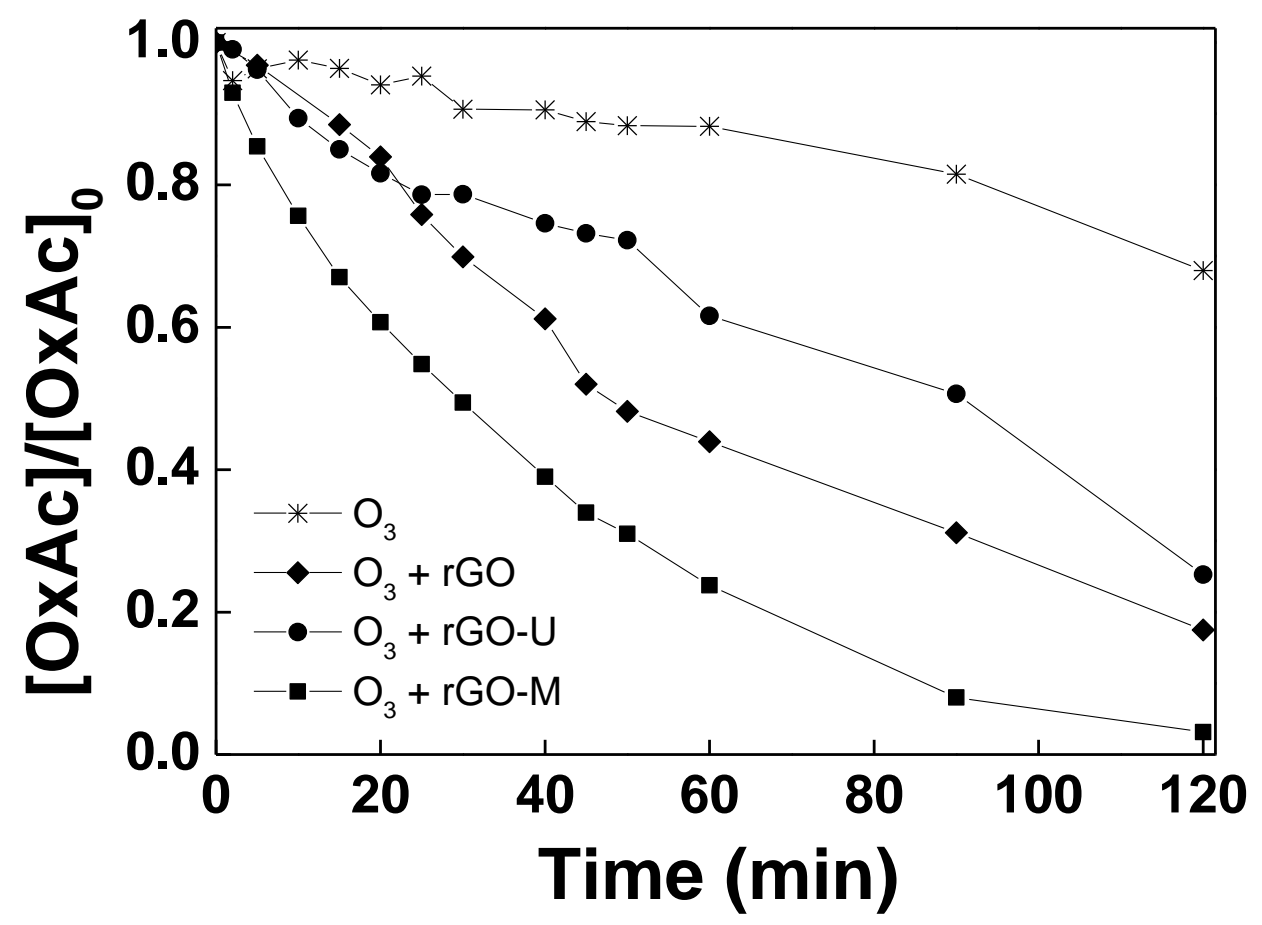

519

520 
521 FIGURE 6

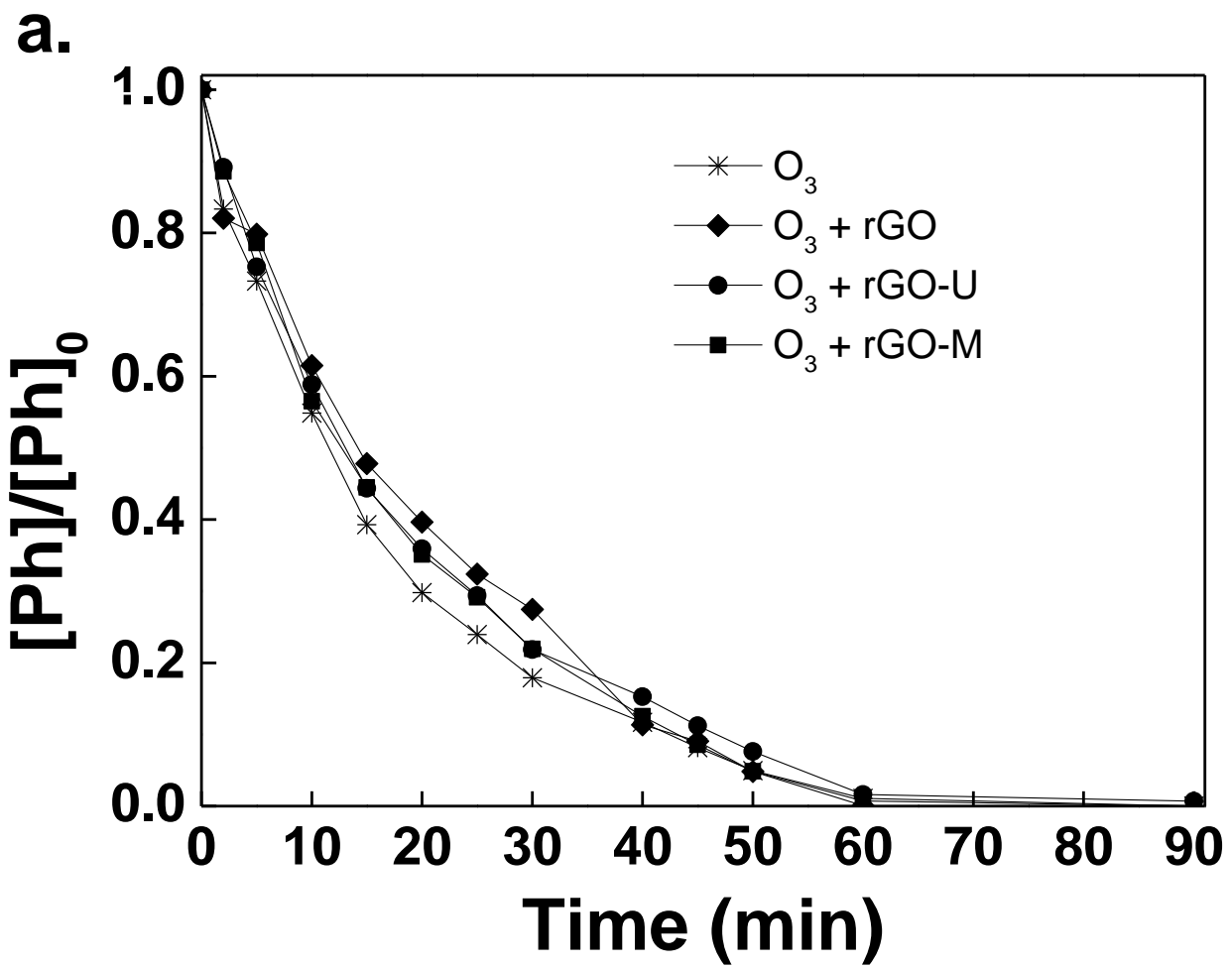

522

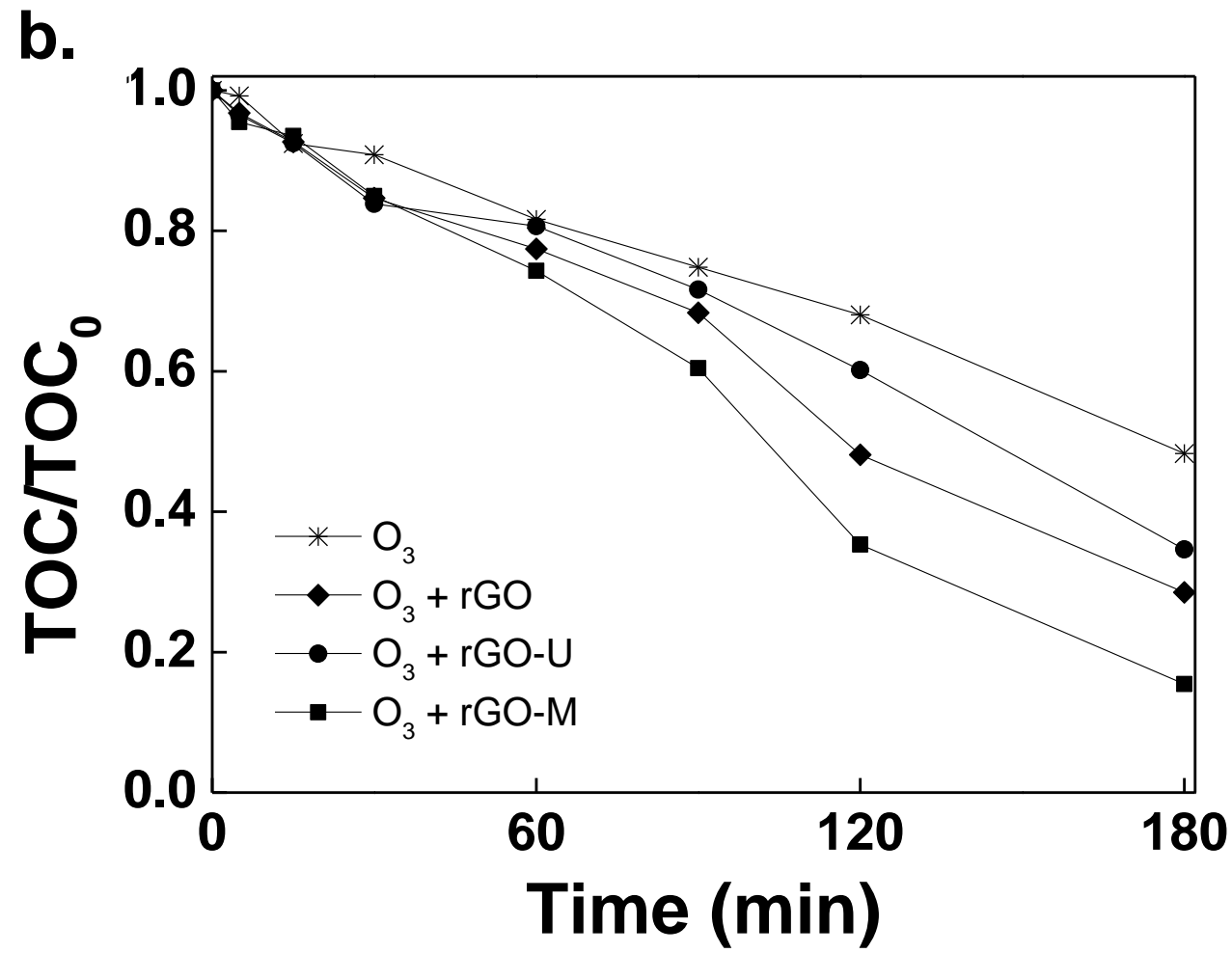


GO
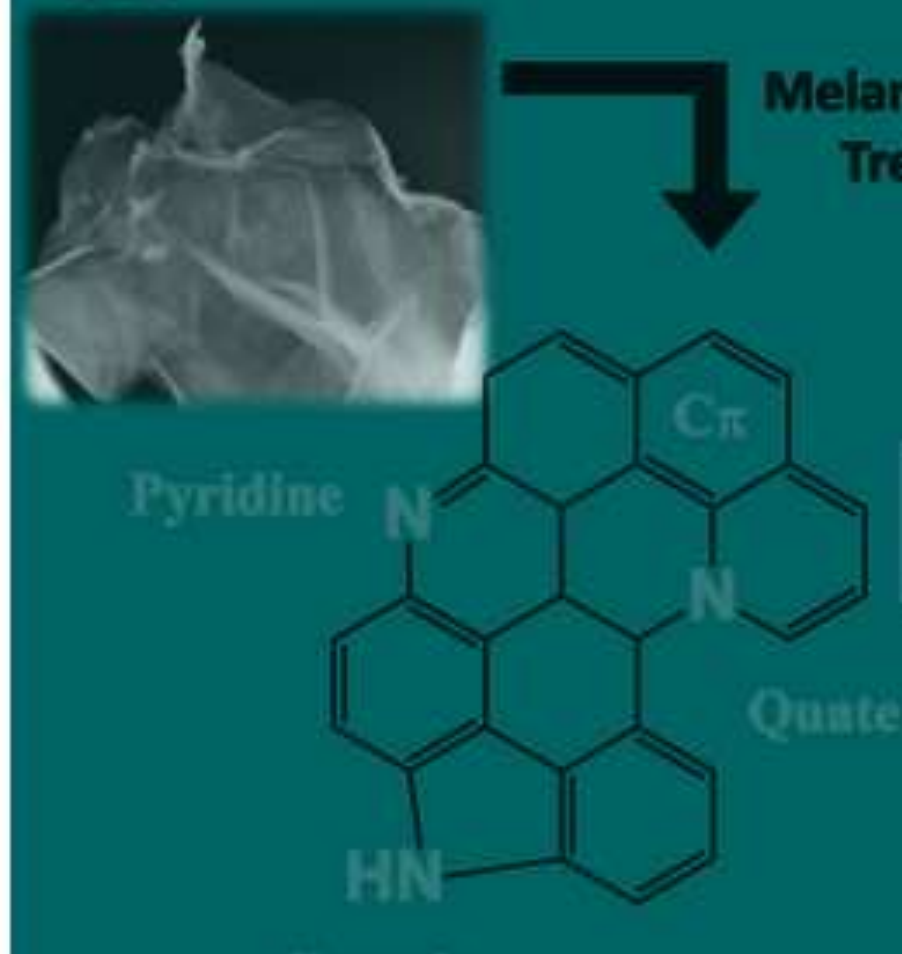

Pyrrole
Catalytic Wet Air

Oxidation (CWAO)

Melamine / Urea

Treatments

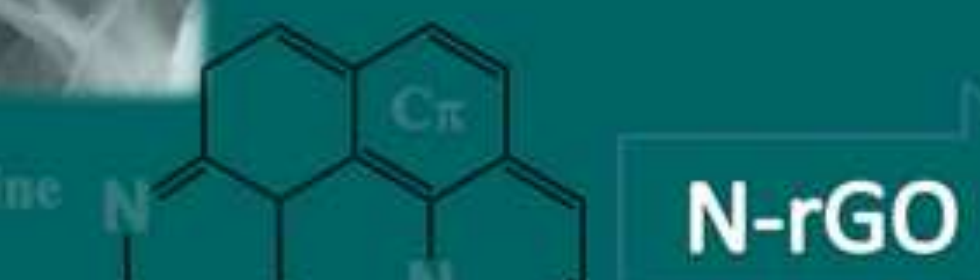

Quaterniny N

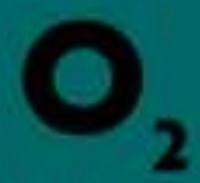

140-160" C 40 bar $\left(\mathrm{O}_{2} ; 7\right.$ bar $)$

\section{N-rGO}

Catalytic
Oxonotion $(\mathrm{CO} x)$

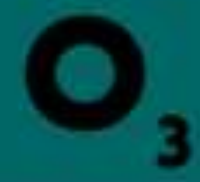

Room temperature Atmospheric pressure

\section{Oxalic Acid}

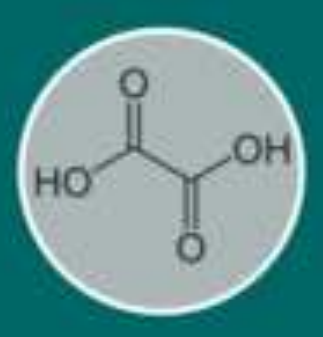

Phenol

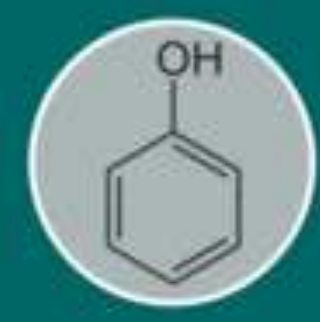

